\title{
Minimally Invasive Interval Appendectomy for Perforated Appendicitis With a Periappendiceal Abscess
}

\author{
Ik Yong Kim \\ Department of Surgery, Yonsei University Wonju College of Medicine, Wonju Severance Christian Hospital, Wonju, Korea
}

\section{See Article on Page 105-110}

Acute appendicitis is the one of the most common conditions requiring surgical intervention, and an appendiceal abscess or phlegmon has an incidence rate of about 3.8\% among patients with a perforated appendicitis [1]. An immediate appendectomy for the treatment of a periappendiceal abscess (PAA) or phlegmon is technically demanding with adhesive loops of the bowel and a distorted anatomy, and the appendiceal stump is difficult to close due to the presence inflamed tissues [2]. In actual practice, not infrequently, even an early laparoscopic surgery will be converted to a more extensive open surgical procedure, such as an ileocecal resection or a right hemicolectomy, due to technical problems or distorted anatomy [3].

In the management of perforated appendicitis with a well-defined abscess and an inflammatory phlegmon seen on an image study, an alternative treatment may be nonsurgical management, including intravenous antibiotics and selective percutaneous drainage. Currently, a treatment widely accepted among surgeons is initial nonoperative management followed by an interval appendectomy rather than an immediate appendectomy, but the management of the appendiceal mass remains a matter of major controversy in current practice. However, many surgeon still agree that an interval appendectomy is to be preferred because the risk for recurrent acute appendicitis is reported to be about $10 \%$ and because a definite diagnosis needs to be established to rule out any underlying malignancy $[4,5]$. The advantage of the interval appendectomy is that the operation is performed at a time when peritoneal contamination has been resolved, poten-

Correspondence to: Ik Yong Kim, M.D.

Division of Colorectal Surgery, Department of Surgery, Yonsei University

Wonju College of Medicine, 20 Ilsan-ro, Wonju 26426, Korea

Tel: +82-33-741-0573, Fax: +82-33-741-0574

E-mail: iykim@yonsei.ac.kr

(c) 2016 The Korean Society of Coloproctology

This is an open-access article distributed under the terms of the Creative Commons Attribution NonCommercial License (http://creativecommons.org/licenses/by-nc/4.0) which permits unrestricted noncommercial use, distribution, and reproduction in any medium, provided the original work is properly cited. tially resulting in fewer intraoperative and/or postoperative complications. Although this advantage has led to the widespread application of drainage/interval appendectomy, published data describing how these patients fare during the interval between percutaneous abscess drainage and minimally invasive surgery are rare.

The superiority of an early laparoscopic appendectomy (LA) over an interval LA has been shown in some reports on patients with a well-formed abscess $[6,7]$. This pilot randomized trial found no major differences in outcomes when comparing an early LA with an interval LA [6]. In another randomized study on appendiceal phlegmon, Blakely et al. [7] concluded that, compared to an interval LA, an early LA significantly reduced the time away from normal activities and the rates of overall adverse events and had a conversion rate comparable to that of an open appendectomy. Schurman et al. [8] also reported that their patients managed with an interval LA were likely to suffer a more negative impact on their quality of life than those managed with an immediate LA. Based on these studies, the issue of whether an interval LA is superior to an early LA for the treatment of an appendiceal phlegmon remains a topic of debate.

As experience with the single-incision technique grows, the role of immediate surgery in the treatment of patients presenting with an abscess deserves to be reconsidered. Conservative management followed by a single-incision laparoscopic interval appendectomy using a multichannel single port appears feasible and safe for the treatment of patients with acute perforated appendicitis with a PAA, as this study shows [9]. However, this study has several limitations, including its retrospective nature, small number of patients, and lack of data on surgical outcomes such as quality of life and pain or cosmesis for both single-port and multiport surgeries. Therefore, further large-scale comparative studies are needed to prove the advantages of this procedure by comparing the outcomes for initial nonoperative management followed by an interval appendectomy to the outcomes for an early laparoscopic appendectomy in patients with perforated appendicitis and a PAA. 


\section{CONFLICT OF INTEREST}

No potential conflict of interest relevant to this article was reported.

\section{REFERENCES}

1. Andersson RE, Petzold MG. Nonsurgical treatment of appendiceal abscess or phlegmon: a systematic review and meta-analysis. Ann Surg 2007;246:741-8.

2. Ahmed I, Deakin D, Parsons SL. Appendix mass: do we know how to treat it? Ann R Coll Surg Engl 2005;87:191-5.

3. Oliak D, Yamini D, Udani VM, Lewis RJ, Arnell T, Vargas H, et al. Initial nonoperative management for periappendiceal abscess. Dis Colon Rectum 2001;44:936-41.

4. Simillis C, Symeonides P, Shorthouse AJ, Tekkis PP. A meta-analysis comparing conservative treatment versus acute appendectomy for complicated appendicitis (abscess or phlegmon). Surgery 2010;147:818-29.
5. Vane DW, Fernandez N. Role of interval appendectomy in the management of complicated appendicitis in children. World J Surg 2006;30:51-4.

6. St Peter SD, Aguayo P, Fraser JD, Keckler SJ, Sharp SW, Leys CM, et al. Initial laparoscopic appendectomy versus initial nonoperative management and interval appendectomy for perforated appendicitis with abscess: a prospective, randomized trial. J Pediatr Surg 2010;45:236-40.

7. Blakely ML, Williams R, Dassinger MS, Eubanks JW 3rd, Fischer P, Huang EY, et al. Early vs interval appendectomy for children with perforated appendicitis. Arch Surg 2011;146:660-5.

8. Schurman JV, Cushing CC, Garey CL, Laituri CA, St Peter SD. Quality of life assessment between laparoscopic appendectomy at presentation and interval appendectomy for perforated appendicitis with abscess: analysis of a prospective randomized trial. J Pediatr Surg 2011;46:1121-5.

9. Bae SU, Jeong WK, Baek SK. Single-port laparoscopic interval appendectomy for perforated appendicitis with a periappendiceal abscess. Ann Coloproctol 2016;32:105-10. 